\title{
On valuing biopharmaceutical product pipelines: an effectuation model and evidence
}

\author{
Mark J. Ahn ${ }^{1}$, Anne S. York ${ }^{2}$, Wei Wu W $^{3}$, Yulianto Suharto ${ }^{1}$ and Tugrul Daim ${ }^{\text {** }}$
}

\author{
* Correspondence: \\ tugrul@etm.pdx.edu \\ ${ }^{1}$ Portland State University, Portland, \\ USA \\ Full list of author information is \\ available at the end of the article
}

\begin{abstract}
New creative approaches are needed to manage emerging biotechnology innovations, regulations, and payor environments to enhance product pipeline productivity, valuation, and risk management. Biopharmaceutical firms must make dynamic resource allocation decisions on their relative levels of internal R\&D and external strategic alliances in furthering their pipelines. As the predominant method of using discounted cash flow (DCF) methodologies may lead to chronic underinvestment and performance, we evaluated the integration of traditional DCF with an effectuation model of analysis. Unlike traditional financial models that begin with the end goal of assumed known cash flows and recursively solve for portfolio optimization, the effectuation model-means, affordable loss, partnerships, and expect the unexpected-begins with resources that are readily available to the firm and then seeks to maintain strategic flexibility to take advantage of environmental contingencies as they arise. Using effectuation principles can provide insight into optimizing pipeline decisions by focusing on the logic of control rather than the logic of prediction. Using empirical data, we found that investors were able to effectively differentiate between the pipeline values of among companies. Overall, these results suggest that the integration of effectuation and DCF provides a lens from which to explore emerging varieties of small and large company innovation in the biopharmaceutical industry.
\end{abstract}

\section{Background}

As many of the past decade's blockbuster drugs, including Pfizer's \$12 billion Lipitor, continue to come off patent, concerns are growing as to whether and how the biopharma industry will replace revenues lost to generics (Kirchhoff and Schiereck, 2011). A report of the President's Council of Advisors (2012) on science and technology warns, "The pharmaceutical industry is facing the largest 'patent cliff' in its history: drugs with annual sales exceeding $\$ 200$ billion will come off patent in the period 2010-2014, resulting in a loss of more than $\$ 100$ billion in sales to generic substitutions; only a small fraction is expected to be replaced by new product revenues (p. vii)." Several studies have noted the R\&D productivity paradox: on one hand, molecular medicine is expanding the numbers of disease targets for more complex unmet medical needs (e.g., Parkinson's, Alzheimer's) and orphan drug diseases which focus on smaller patient populations (e.g., Gaucher's disease, myeloproliferative disorders), and on the other hand, drug

\section{Springer}


development in novel, complex diseases increases the risk of failure in the face of rising R\&D costs (Pammolli et al. 2011). ${ }^{1}$ As noted by Piccart-Gebhart (2014) at the 41 st Karnofsky Memorial Award Lecture:

The pharmaceutical industry is under extreme financial pressure...Given increasingly cost-constrained health care systems, limited patent durations on blockbuster drugs, competition from generics, a more demanding regulatory environment, diminishing marketing exclusivity, and progressively smaller markets resulting from the rapidly increasing molecular segmentation of the populations of patients...companies are being forced to overhaul their drug development strategies (p. 348).

As such, new creative approaches are needed to manage emerging biotechnology innovations, regulations, and payor environments to enhance product pipeline productivity, valuation, and risk management, all of which are critical to future industry development and national competitiveness (Beach, 2011; Ford et al. 2008; Lindgren and Packendorff, 2011; Roy, 2012).

Typically, large biopharma firms create drug development pipelines in three ways: internal development, strategic alliances (e.g., joint ventures, alliances, co-promotion, codevelopment), and mergers and acquisitions (Pavlou and Belsey, 2005). Studies (York et al. 2011) have examined relative success rates of different acquisition strategies in the biopharma industry, finding that horizontal mergers, which tend to reduce costs through scale economies, outperform vertical mergers, in which large pharma firms typically acquire innovation rich, and cash poor small biotech firms to gain access to new and emerging products. However, even the relatively more successful horizontal acquisitions often destroy value for the acquiring firm (York et al., 2011). Further, Kirchhoff and Schiereck (2011) concluded that at least some of this value destruction stems from overpayment due to acquisition premiums, often for firms with high profile drugs in late-stage clinical trials or those that have recently gained FDA approval for such products. However, because the drug development process is inherently risky and expensive, large public biopharma firms seem to prefer investing in what they consider "sure bets," even if they may end up overpaying. This practice results from perceiving that the risk of overpaying for late-stage drugs is less serious than the uncertainty associated with valuing firms and products in earlier stages of development (Hartmann and Hassan, 2006).

Further, research does support the widespread practice among biotech industry analysts to base firm valuation either on existing cash flows (based on the assumption that future success can be predicted from past performance) or on cash flows based on market data that can be more readily measured, such as revenues expected from drugs that are near FDA approval and thus market launch (Löfqvist, 2009). This is particularly the case in the biotech industry where "go/no go" decisions are stage-gated to each phase of product development. ${ }^{2}$ Analysts also may overestimate discount rates for cash flows from early stage products, thus dooming them to rejection because their lengthy time lines result in low net present values. Each of these traditional valuation practices may lead to under valuation and thus underinvestment in earlier stage drug development projects, even though some will offer high or breakthrough innovation potential with the option to abandon them at multiple stages of development (Newton et al. 2004). 
An alternative that would seem to resolve traditional cash flow valuation problems is to use "real options" techniques. Real options offer firms the right to acquire the present value of expected cash flows by making an irreversible investment on or before the date the opportunity is no longer available (the option expiration date). Although this technique sounds similar to net present value (NPV), real options only have value when the decision to invest is actually made, thus committing the firm to an irreversible cost. In the case of long timeframe investments in uncertain environments, breaking up projects into stages, each of which has a real option value, can reduce risk. Thus, real options have been presented as a more robust alternative to valuing biopharma pipelines (Hartmann and Hassan, 2006; Kumaraswamy, 1998). Reasons for this include the high degree of uncertainty and disagreement regarding future biological disease pathways, the long timelines and dynamic capabilities involved in novel drug development, the large sums of money required to conduct clinical trials sufficient to gain FDA approval, and the high historical risk of failure (Ahn and Meeks, 2008; Ahn et al. 2010; Brink and Holmén, 2009; Roy, 2012).

Recognizing that traditional valuation models may result in drug development decisions that reward overpayment for products in later stages of the FDA approval process and also that real options models have not been embraced by industry analysts for the reasons outlined above, we began searching for alternative strategic frameworks and valuation models that might more correctly incorporate the value of early stage products. Our search led us generally to the entrepreneurship literature and, more specifically, to Sarasvathy (2001) effectuation model. While initially derived as a model for predicting the success or failure of early stage startups, unlike traditional financial models that begin with the end goal and work backwards, the effectuation model begins with resources that are readily available to the firm and then stays flexible enough to take advantage of environmental contingencies as they arise. In that sense, it is more similar to real options than to traditional discounted cash flow models.

In this paper, we test the effectuation model against the more traditional model of discounting existing or late-stage cash flows and also look at which dimensions of effectuation are most relevant to biopharma pipeline valuation. We believe our results suggest that, if conceived and operationalized in a way that fits the highly uncertain biopharma industry environment, applying at least some elements of the effectuation model to biopharma pipeline valuation may provide a more robust approach to pipeline development strategy for both practice and research.

\section{Literature review}

\section{Competing models of valuation}

Traditional finance suggests that decisions such as valuing a going concern are made under conditions of certainty and thus are economically rational. The discounted cash flow valuation model used by most financial analysts is based on this idea. Essentially, present cash flows are known, future cash flows can be reasonably estimated, and the level of risk and thus required rate of return is a given or at least can be accurately estimated using historical stock price covariance with the market and/or that of benchmark companies of the same size, stage of development, and/or therapeutic area (Stewart et al. 2001). 
However, the usefulness and accuracy of such "rational" models are reduced when long time horizons and high uncertainty are present as they are in the biopharma industry (Iskin et al. 2011). On the one hand, drug development costs have rapidly grown from $\$ 100$ million constant dollars in 1975 , to $\$ 300$ million in 1987 , to $\$ 800$ million in 2000 , and to over $\$ 1.3$ billion in 2005 . Further, the complexity (i.e., increased number of median procedures, globalization, staffing) and trial length (e.g., average study in 1999 was 460 days to 780 days in 2005) have significantly increased. However, the probability of success remains modest, with FDA approval rates by stage of development at preclinical (8 \%), Phase 1 (21), Phase 2 (28), Phase 3 (58 \%) in 2011 (DiMasi, 2013; Kola and Landis, 2004; Roy, 2012).

As a result, even analysts who follow the biopharma industry seem to agree that forecasting expected cash flows from, and the risk associated with, drugs under development is a frustrating and imprecise exercise. Instead, they tend to use current or easily estimated, late-stage, cash flows as a proxy for future cash flows, presumably because firms that have learned to develop and commercialize new drugs will continue to do so at the same rate as in the past (Löfqvist, 2009). Retail investors, who are one more step removed from the information and analysis process, may be even more likely to assume that the past is the best predictor of the future.

To take into account these longer timeframes and higher level of risk in the biopharma industry, in the past few decades finance theorists have suggested using a real options approach (Hartmann and Hassan, 2006). Real options theory, unlike financial options theory, uses the value of the underlying asset (in this case, biopharma drugs under development/in the corporate pipeline) as a proxy for future cash flows and then estimates a value based on the time remaining for the "option" to expire (called the strike date) and the risk that the event (e.g., FDA approval and commercialization) will not take place. This approach has many of the same shortcomings of having to estimate future cash flows, although the valuation technique is far more sophisticated.

Because the estimates are so difficult to develop and the confidence levels in the information needed tend to be low, very few empirical research papers have attempted to operationalize and test real options models, although quite a few papers have developed theoretical models. The results of such attempts tend to reflect the use of a very precise tool with very crude inputs, the value of which is questionable. As a result, this valuation technique is not much used by researchers, not to mention practicing analysts (Harrison and Lerer, 2002; Hartmann and Hassan, 2006). A new way of thinking about how to value success under conditions of high uncertainty-effectuation-may offer a more robust theoretical framework and approach to more valuing drug development pipelines.

\section{An effectuation model and hypotheses}

Effectuation theory differs from more traditional causal models of venture success in the sense that it refers to "a set of means as given and focus on selecting between possible effects that can be created with that set of means," while causal models rely on prediction and processes that "take a particular effect as given and focus on selecting between means to create that effect" (Sarasvathy, 2001, p. 245). The original effectuation model consists of four dimensions: means, affordable loss, partnership, and expecting the unexpected (Read et al. 2009) (Table 1). 
Table 1 Effectuation elements and dimensions

\begin{tabular}{ll}
\hline Effectuation element & Dimension \\
\hline Means & "What I know," "who I am," and "who I know" \\
Affordable loss & $\begin{array}{l}\text { Risk-taking propensity and the ability to thrive through a setback } \\
\text { Partnerships }\end{array}$ \\
$\begin{array}{l}\text { Collaborations with stakeholders and organizations willing to make a significant } \\
\text { commitment to product and market development }\end{array}$ \\
$\begin{array}{l}\text { Embrace surprises that arise from uncertain situations, remaining flexible rather than } \\
\text { tethered to existing goals (Read et al., 2009; Sarasvathy, 2001) refer to this effectuation } \\
\text { dimension as "leverage contingency" and define it as a "willingness to change products, } \\
\text { customize." }\end{array}$ \\
\hline
\end{tabular}

Effectuation has been widely explored in entrepreneurship (Sarasvathy, 2008) but has also been considered in the context of corporate R\&D (Brettel et al. 2012), management (Augier and Sarasvathy, 2004; Hitt and Duane, 2002), economics (Dew et al. 2004), finance (Wiltbank et al. 2009), and marketing (Read et al., 2009). However, to our knowledge, our research is the first to explore its use specifically within the context of the biopharma industry and to apply it to valuing drug development pipelines. We first describe below how each of the four effectuation concepts have traditionally been defined and how they might be operationalized in this new biopharma industry context. We then end the discussion of each concept with our hypotheses.

Several interesting observations about empirical tests of the effectuation model seem relevant to mention up front. First, the same concepts have been operationalized on multiple levels of analysis, including the individual and firm. Also, surveys have been the predominant method of data collection which focused on exploring new venture success in terms of individual decision-making (Dew et al., 2004). Our research differs from these prior studies in that we look only at existing firm level variables, a precedent suggested and supported by Brettel et al. (2012) who collected their data using surveys of European technology firms rather than adopting archival financial data as proxies. As such, their survey-based results are based on management perceptions.

Next, we describe each effectuation dimension-means, affordable loss, partnerships, and expect the unexpected-in the context of the biopharma industry (Table 1):

1. Means: Traditionally, the "means" construct is a three dimensional variable: "what I know," "who I am," and "who I know." "What I know" tends to be defined as domain specific expertise as well as more general variables such as personality, gender, and management experience. This dimension seems to be operationalized primarily at the individual level. "Who I am" has been operationalized at both the individual level of analysis (such as propensity for risk and self-efficacy) and the firm level (such as patents, capital, and internal R\&D). From a face validity perspective, the "what I know" and "who I am" dimensions would seem to overlap. "Who I know" includes family and friends who are entrepreneurs and links to universities and institutions in the innovation process (Hemlin, 2009).

Because pharmaceutical firms enjoy high profit margins percentages, most multinational biopharmaceutical companies have significant absolute financial "means" or resources to deploy, including large cash balances, borrowing capacity, and stock market values. These means allow them to invest heavily in R\&D, among other things. However, their decisions on how much to invest and on what 
segments can differ significantly depending on their degree of diversification and priorities. For example, a diversified biopharma firm like Johnson and Johnson (J\&J) gains about $37 \%$ of sales from its biopharma segment, while a more focused biopharma firm such as Biogen gains $100 \%$ of revenues from drug sales. While both earn about the same profit margins on their biopharma sales (24.4\% for J\&J and $23.5 \%$ for Biogen), in absolute terms, the internally generated cash available to a corporate giant like J\&J ( $\$ 15$ billion total, $\$ 6.1$ billion from biopharma) dwarfs the internally generated cash available to Biogen ( $\$ 1.2$ billion).

2. Affordable loss: By "affordable loss," traditional effectuation studies typically mean risk-taking propensity and the ability to thrive through a setback. In this context, the affordable loss dimension builds on the resource based view (RBV) of strategy (Barney, 1991) which posits that firms gain competitive advantage from having resources that provide them with unique sources of competitive advantage. These resources may fall into a variety of categories, including physical, financial, human, and organizational, and confer competitive advantages based on the value, rareness, uniqueness (inimitability), and embeddedness in the organization fabric. The difficulty other firms experience in imitating these successful firms' resources is explained by the amount of time it takes to create and develop them (often decades), as well as the difficulty (in the case of embeddedness) others experience in identifying them as sources of competitive advantage. RBV posits that the more rare, unique, and embedded the resource, the greater the source of competitive advantage, so long as those resources fit the environment in which the firm operates. Further, Makadok (2001) connects resources to the term "capabilities," defining a capability as "a special type of resource-specifically, an organizationally-embedded, non-transferable firm-specific resource whose purpose is to improve the productivity of the other resources possessed by the firm" (p. 389). He concluded that capabilities cannot be bought, rather, they must be built. Further, these internal capabilities, combined with external partnerships, may be seen as a flexible innovation system (Su et al. 2009).

An example of a large multinational biopharma leveraging its resources to shift from a traditional internal $R \& D$ model to biopharmaceutical alliances to further its product pipeline is Bristol-Myers Squibb Company (BMY), which has been strategically aligning with small and mid-sized drug developers and biotech companies. (Ahn, Wu, and Rahman, 2010). BMY strategically targets companies whose products and technologies address unmet medical needs and build on BMY's R\&D strengths and/or create new areas of expertise. The "String of Pearls" strategy formalized in 2007, threads together a library of compounds and portfolio of technologies for the purpose of accelerating the discovery, clinical development, and commercialization of new therapies across a broad range of therapeutic areas. James $\mathrm{M}$. Cornelius, chairman and chief executive officer, Bristol-Myers Squibb (BMS) noted about their $\$ 2.1$ billion acquisition of Medarex:

Medarex's technology platform, people and pipeline provide a strong complement to our company's biologics strategy, specifically in immuno-oncology. With its productive and proven antibody discovery capabilities, ability to generate interesting 
therapeutic programs and unique set of pre-clinical and clinical assets in development, Medarex represents what we're looking for in terms of our String of Pearls strategy. This acquisition is another important step in our BioPharma transformation.

Conversely, BMY's acquisition of Inhibitex in Phase 3 clinical development for hepatitis $\mathrm{C}$ virus $(\mathrm{HCV})$ for $\$ 2.5$ billion or $167 \%$ premium resulted in a total failure. After only 8 months, the lead drug trial was discontinued due to a patient death, and most of the company was disposed with a $\$ 1.8$ billion write-off. As such, a firm's absolute as well as relative ability to absorb losses may determine its willingness to invest in risky, long-term projects such as novel drug development.

3. Partnerships: Effectuation theory frames partnerships as collaborations with stakeholders and organizations willing to make a significant commitment to product and market development. Read et al. (2009) distinguish the "means" dimension from the "who I know" dimension from the "partnerships" dimension by determining whether success depends on the studied firm ("means") or the other party ("who I know"-typically as a result of money, equity, or a product changing hands).

In the biopharma context, the vast majority of the over 600 public and 8000 private companies worldwide have no revenues or earnings, which means that their investment is funded through grants, public or private equity, and/or through resource partnerships with larger, better capitalized public biopharma firms. The small percentage of these firms that are successful in moving into later stages of clinical trials or actually receiving FDA approval to market the drug are often acquired by larger biopharma firms in these later stages (Kirchhoff and Schiereck, 2011). Thus, for large, well-established firms, partnering with and/or later acquiring smaller biotech companies provides a viable option to committing a firm's R\&D investment capital to internal development programs (Ahn, Meeks, et al., 2010). These partnerships, collaborative agreements, and joint ventures create powerful innovation network effects (Hemphälä and Magnusson, 2012), as well as also allow both firms to learn to work together, providing an option on possible later acquisition.

Despite the greater information asymmetry associated with early stage novel technologies (e.g., stem cells, checkpoint inhibitors, gene therapy, cancer vaccines, RNAi), in our view, a number of signaling mechanisms may help investors discern/ discriminate among firms' pipelines, including clinical data (such as announcement of clinical results at medical conferences), publicly announced partnership deals (such as licensing, co-development, co-promotion, all of which provide technology validation), and/or institutional investment by specialist mutual and hedge funds, which provides signaling mechanisms to broader investor groups (Gulati and Higgins, 2003; Nicholson et al. 2002). For example, Agios Pharmaceuticals, an early stage drug development company which focused on cancer metabolism with a marquee research partnership with large biopharma Celgene, successfully completed an IPO at $\$ 18$ which overshot the range of \$14-16, raised an additional \$106 million, and soared $60 \%$ on its first day of trading-sending the market capitalization to over $\$ 800$ million. 
4. Expect the unexpected: Effectuation principles encourage companies to embrace surprises that arise from uncertain situations, remaining flexible rather than tethered to existing goals (Read et al., 2009; Sarasvathy, 2001) refer to this effectuation dimension as "leverage contingency" and define it as a "willingness to change products, customize."

While all large biopharmaceutical companies have a pressing and ongoing need for new products, they have approached pipeline and product investment and development differentially, in the sense that some rely on internal development and research partnerships, while others rely on purchasing external R\&D and/or smaller firms typically in later stages of FDA approval through mergers and acquisitions. Illustrating these different approaches, Pfizer has heavily relied on multibillion dollar acquisitions which have included Warner-Lambert in 2000, Pharmacia in 2002, Wyeth in 2009, King Pharmaceuticals in 2010; and Roche has relied on internal development and partnership (e.g., Genentech partnership to grow a pipeline of blockbuster oncology products such as Herceptin ${ }^{\circledast}$ (trastuzumab), Rituxan $^{\oplus}$ (rituximab), and Avastin ${ }^{\oplus}$ (bezicuzimab)) each with greater $\$ 5$ billion in 2012 annual revenues. As discussed above, there is a tradeoff between the perceived risk of overpaying for late-stage products, often obtained through mergers and acquisitions and the uncertainty of valuing internally developed earlier stage products (Ford et al., 2008). In the biopharmaceutical industry, more positive value may be created by drugs in the earliest phases of development, rather than the ones closer to FDA approval, and/or by failed drugs repurposed to another use (Beach, 2011). For example, Viagra $^{\oplus}$ (sildenafil) was first synthesized in 1989 by two Pfizer chemists at the company's Sandwich, Kent research facility in England. Viagra was initially studied for use in hypertension (high blood pressure) and angina pectoris (a symptom of ischemic heart disease). After Phase II testing of sildenafil for angina failed to show promising results, Pfizer decided to pursue its use for erectile dysfunction rather than for angina. The drug was patented in 1996 and approved for use in erectile dysfunction by the US Food and Drug Administration in 1998 (and expanded approvals were obtained for pulmonary hypertension in 2005). Sales of Viagra exceeded $\$ 2$ billion in 2012 revenues.

Conversely, a value-destroying variation on the "unexpected" is when unanticipated safety signals arise, even after extensive clinical studies. For example, Biogen-Idec and Elan's Tysabri (natalizumab) was originally approved for all relapsing forms of multiple sclerosis (relapse-remitting, secondary-progressive, and progressiverelapsing) in 2004. However, 4 months after its approval in February 2005, the manufacturer withdrew natalizumab voluntarily after two fatal cases of progressive multifocal leukoencephalopathy, and the stock price fell from $\$ 66$ to $\$ 38$. Eventually, the drug was reapproved in June 2006 after an extensive safety review and heavy lobbying by patients, and Tysabri reached $\$ 5.5$ billion in 2012 revenues.

Effectuation principles can provide insight into optimizing pipeline decisions by focusing on the logic of control rather than the logic of prediction. Juxtaposing effectuation with discounted cash flow (DCF) may lead to new insights to addressing chronic underinvestment in the biopharma industry by focusing on what can be done with 
available resources rather than what ought to be done, affordable loss rather than expected return, partnerships rather than competitive analyses, and leveraging contingencies rather than avoiding them (Sarasvathy, 2001, 2008). Thus, using an effectuation lens, we pose the following hypotheses in the context of the large multinational biopharmaceutical companies:

- $\mathrm{H}_{1}$ : Biopharmaceutical companies with higher absolute R\&D expense will have higher performance in terms of growth in revenues, net income, valuation, and Price-Earning (PE) multiples relative to peer competitors.

- $\mathrm{H}_{2:}$ Biopharmaceutical companies with higher R\&D expense as percent (\%) of revenues will have higher performance.

- $\mathrm{H}_{3 \text { : }}$ Biopharmaceutical companies with higher pipeline valuation as a percent of overall valuation will have higher performance.

- $\mathrm{H}_{4}$ : Effectuation dimensions will have higher predictive power than the traditional discounted value of present cash flow models.

\section{Methods}

To test our effectuation theory model and hypotheses against the predominant classic discounted cash flow/legitimacy model described above, we focused on 11 of the largest multinational biopharmaceutical firms during the 2000-2012 period. These leading firms ranged in size from $\$ 5$ to 67 billion in 2012 revenues, $\$ 1$ to 8.7 billion in net income, and $\$ 10$ to 200 billion in market value using the Biocentury database.

All of these companies made explicit and public their decisions on the number of pipeline projects to pursue, determined the degree of reliance on internal development versus external partnerships, and decided when to increase investment or discontinue projects. For example, a recent biopharmaceutical analyst noted using a DCF approach to valuation:

We are lowering our AZN [Astra Zeneca] EPS [earning per share] to reflect the impact of modestly lower near-term sales but overall higher spending expectations. Management commentary...highlighted increased R\&D and SG\&A spending to support the renewed commitment to R\&D...to advance the Phase I/II oncology and respiratory pipelines while investing behind new product acquisitions (Pearl Therapeutics, Omthera). Key internal [pipeline product] readouts and data presentations are expected for benralizumab (anti-IL-5; eosinophilic asthma \& COPD), tralokinumab (anti-IL-13 in severe asthma) \& MEDI-4736 (anti-PD-L1 in solid tumors). Our DCF valuation increases to $\$ 50$ from $\$ 47-\$ 48$ on a lower Pharma group discount rate (Fernandez \& Arabi, 2013).

On average, all of these companies used external partnering for $34 \%$ of their product pipelines (ranging from a low of $17 \%$ to a high of $57 \%$ ). Also of note, these companies employed external partnering at increasingly later stages of development with Phase I (15\%), Phase II (24\%), Phase III (38 \%), products awaiting approval (34 \%), and marketed products (45\%) of the time (Fig. 1).

As a result of independent decisions on how much of current cash flow to reinvest in various pipeline development products, performance in terms of revenues, net income, 


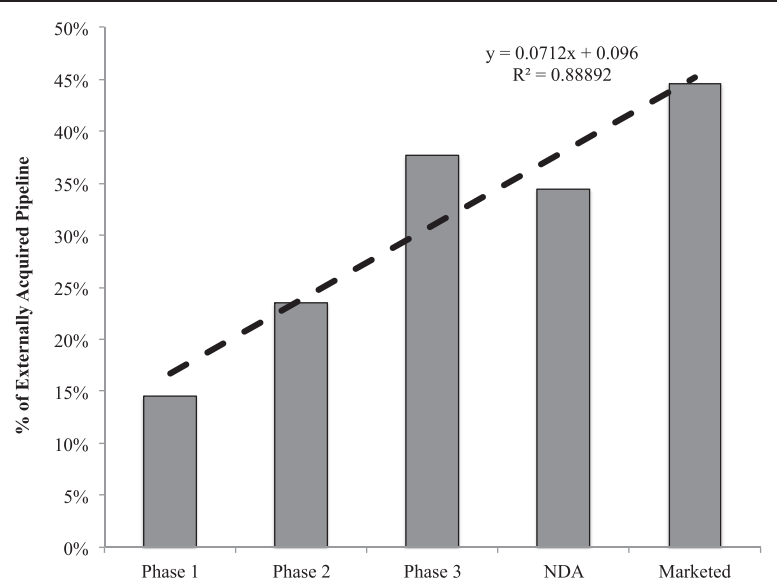

Fig. 1 Percent of externally acquired product pipeline by stage of development for large biopharmaceutical companies

market capitalization, and PE (price-earnings) multiples change over time. We obtained pipeline data from Biocentury which tracks technology platforms, product pipelines, and financial performance for public and private biopharmaceutical companies in the USA, Europe, Canada, and the Asia-Pacific region. In addition, we obtained financial performance data such as stock prices, shares outstanding, market capitalization, S\&P 500 and BTK (Biotech) indices, net income, R\&D expense, revenues from SEC filings, and Yahoo Finance. We obtained 10-year US Treasury interest rates to determine historical costs of capital.

Of note, biotechnology firms have consistently outperformed traditional multinational pharmaceutical companies in the last 20 years. In addition, with increasingly greater financial resources and global capabilities, large pharmaceutical companies are increasingly transforming into biopharmaceutical companies (e.g., Roche acquisition of Genentech in 2009) (Fig. 2).

Thus, the independent and dependent variables are operationalized as seen in Table 2:

Relative to DCF NPV analysis (DiMasi, 2013; Nickisch and Bode-Greuel, 2013), we explore a broader effectuation framework to consider the relative magnitude and intensity of R\&D (i.e., R\&D expense in absolute dollars and as a percent of revenues, pipeline valuation) over time. In turn, the dependent variables of interest are performance that is derived from pipeline development decisions in terms of revenues, net income, market valuation, and PE multiples that can compound competitive advantages.

The measures of both input variables and performance variables in our model were multivariate. Hence, analytical methods that can be used include the following: (1) canonical correlation analysis (CCA) which provides a way of making sense of crosscovariance matrices by considering commonalities among sets of variables; (2) separate ordinary least squares (OLS) regression to estimate unknown parameters in a linear regression model, which will not produce multivariate results or information concerning dimensionality; and (3) multivariate multiple regression provides simultaneous observation and analysis of more than one outcome variable but does not provide information on dimensionality (Afifi and Clark, 2004; Pedhazur, 1997).

One major reason for use of multivariate procedures for our model is that it keeps Type I error to a minimum (Fan, 1997; Sherry and Henson, 2005; Thompson, 1985, 


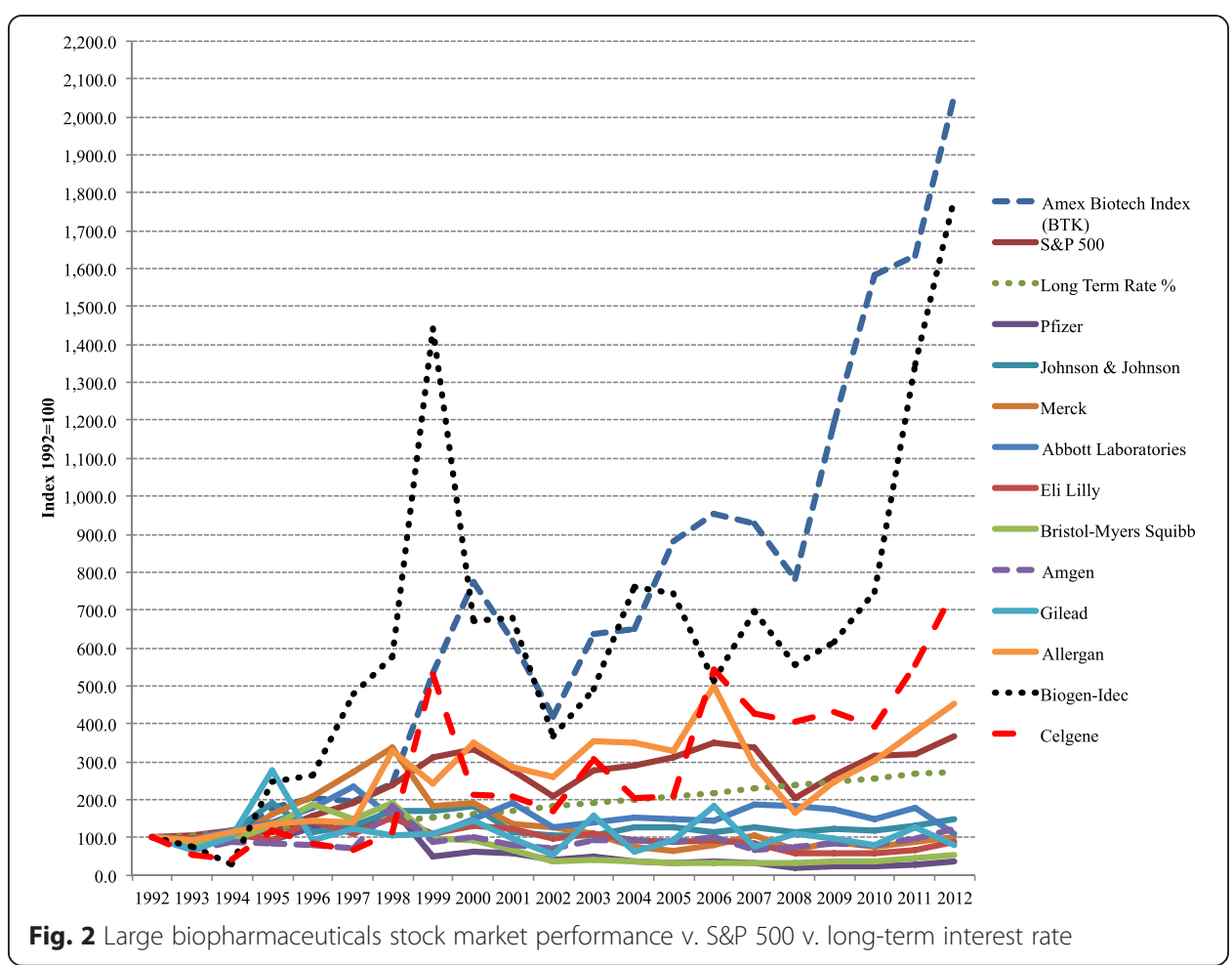

1991). CCA is used to identify and measure the associations between two sets of variables. CCA is appropriate in the same situations where multiple regressions would be but where there are multiple intercorrelated outcome variables. CCA was chosen as our model because it determines a set of canonical variates, orthogonal linear combinations of the variables within each set that best explains the variability both within and between sets.

Relationships between sets of multiple dependent variables are analyzed with CCA (Darlington et al. 1973; Hair et al. 1986; Levine, 1977; Tucker et al. 1980). Furthermore, in a CCA, there will be as many canonical functions as there are variables in the smaller of the two variable sets (Sherry and Henson, 2005). In our study, the data on

Table 2 Effectuation model dimensions and metrics

\begin{tabular}{|c|c|c|}
\hline & Independent Variable & Variable \\
\hline $\mathrm{H} 1$ & R\&D expense in absolute dollars (\$) & Revenues \\
\hline $\mathrm{H} 2$ & $R \& D$ expense as percent $(\%)$ of revenues & Valuation \\
\hline $\mathrm{H} 3$ & Pipeline valuation as a percent $(\%)$ of total valuation & Net Income \\
\hline $\mathrm{H} 4$ & All effectuation dimensions & $\begin{array}{c}\text { Price- } \\
\text { Earning (PE) }\end{array}$ \\
\hline
\end{tabular}


the three input variables and the four performance variables were canonically correlated to determine if any significant relationships existed $(p<0.001)$.

CCA was conducted using the three input variables ( $\& \& D$ expenses in absolute dollars (\$); R\&D expenses as percent (\%) of revenues; pipelines valuation as percent (\%) of total valuation) as predictors of the four performance variables (i.e., revenues, market valuation, net income, price-earning ratio) to evaluate the multivariate-shared relationship between the two variable sets.

\section{Results and discussion}

The analysis yielded three functions with squared canonical correlations $\left(R_{c} 2\right)$ of 0.902 , 0.330 , and 0.021 for each successive function, as shown in Table 6. Table 7 indicates that collectively, the full model across all functions was statistically significant using the Wilks's lambda $(\lambda)$ of $0.064, F(12,455.36)=69.36, p<0.001$. Accordingly, we can reject the null hypothesis that there was no relationship between the variable sets and conclude that there probably was a relationship. The detailed analysis results are in the Appendix (Tables 5, 6, 7, 8, 9, 10, 11, 12 and 13)

Because Wilks's $\lambda$ represents the variance unexplained by the model, $1-\lambda$ yields the full model effect size in an $r^{2}$ metric. Thus, for the set of three canonical functions, the $r^{2}$ type effect size was 0.936 , which indicates that the full model explained a substantial portion of $93.6 \%$, of the variance shared between the variable sets.

Further, the dimension reduction analysis allows us to test the hierarchal arrangement of functions for statistical significance. As noted in Table 8, the full model (Functions 1 to 3 ) was statistically significant, $F(12,455.36)=69.36, p<0.001$. Functions 2 to 3 was also statistically significant, $F(6,346)=13.57, p<0.001$. Function 3 to 3 (which is the only function that was tested in isolation) did not explain a statistically significant amount of shared variance between the variable sets, $F(2174)=1.885, p=0.155$.

Given the effects for each function of the squared canonical correlation $\left(R_{c} 2\right)$-only the first two functions were considered noteworthy in the context of this study (90.2 and $33.0 \%$ of shared variance, respectively), as shown in Table 5. The last functions only explained $2.1 \%$ of the remaining variance in the variable sets after the extraction of the prior functions.

Table 3 presents the standardized canonical function coefficients and structure coefficients for Functions 1 and 2 . The squared structure coefficients $\left(r_{s} 2\right)$ are also given as well as the communalities $(h 2)$ across the two functions for each variable.

Note: Table 3 summarized Tables 9, 10, 11, and 12. Structure coefficients $\left(r_{s}\right)$ greater than $|0.45|$ are italicized. Communality coefficients $(h 2)$ greater than $45 \%$ are italicized (following a convention in many factor analyses). Coef $=$ standardized canonical function coefficient, $r_{s}=$ structure coefficient, $r_{s} 2=$ squared structure coefficient, and $h 2=$ communality coefficient.

Looking at the Function 1 coefficients, we can see that relevant dependent variables are primarily sales and net income, the expansion of which is the culmination of strategic choices (i.e., internal versus external R\&D, ability to replace revenues lost to patent expiries). This conclusion is supported by the squared structure coefficients $\left(r_{s} 2\right)$, which indicated the amount of variance the observed variable could contribute to the synthetic performance variable. Furthermore, with the exception of the price-earnings ratio, all of these variables' structure coefficients had the same sign, indicating that they 
Table 3 Standardized canonical function and structure coefficients

\begin{tabular}{|c|c|c|c|c|c|c|c|}
\hline \multicolumn{8}{|c|}{ Canonical correlation analysis for Function 1 and 2} \\
\hline \multirow[b]{2}{*}{ Variable } & \multicolumn{3}{|c|}{ Function 1} & \multicolumn{3}{|c|}{ Function 2} & \multirow[b]{2}{*}{$h^{2}(\%)$} \\
\hline & Coef & $r_{s}$ & $r_{s}^{2}$ & Coef & $r_{s}$ & $r_{s}^{2}$ & \\
\hline Sales & 1.032 & 0.999 & $99.80 \%$ & 1.326 & 0.019 & $0.04 \%$ & $99.84 \%$ \\
\hline Income & -0.037 & 0.897 & $80.51 \%$ & -1.541 & -0.256 & $6.57 \%$ & $87.08 \%$ \\
\hline MarketVa & -0.030 & 0.117 & $1.38 \%$ & 0.746 & 0.725 & $52.59 \%$ & $53.97 \%$ \\
\hline PriceEar & -0.027 & -0.210 & $4.41 \%$ & 0.140 & 0.273 & $7.45 \%$ & $11.85 \%$ \\
\hline$r_{c}^{2}$ & & & $90.20 \%$ & & & $33.00 \%$ & \\
\hline RnDExpen & 0.943 & 0.988 & $97.55 \%$ & 0.846 & 0.023 & $0.05 \%$ & $97.61 \%$ \\
\hline RnDperce & -0.155 & -0.314 & $9.87 \%$ & -0.094 & -0.004 & $0.00 \%$ & $9.88 \%$ \\
\hline ValuePip & -0.030 & -0.661 & $43.72 \%$ & 1.308 & 0.749 & $56.17 \%$ & $99.90 \%$ \\
\hline
\end{tabular}

are all positively related. In this case, the price-earnings ratio is inversely related to the other performance variables.

Across both Functions, R\&D intensity-whether measured as absolute dollars or relative percent of valuation-drives financial performance. Regarding the independent variable set in Function 1, R\&D expenses in absolute dollars (\$) and pipelines valuation as percent (\%) of total valuation variables are the primary contributors to the independent variables. Because the structure coefficient for R\&D expenses in absolute dollars (\$) is positive, it is positively related to all of the performance variables, with the exception of price-earnings. $R \& D$ expenses as percent (\%) of revenues and pipelines valuation as percent (\%) of total valuation are positively related to price-earnings variable and negatively related with sales, market valuation, and net income.

Moving to Function 2, the combination of canonical function coefficient and structure coefficient in Table 3 suggests that relevant dependent variable is market valuation. As for the independent variables, pipeline valuation as percent (\%) of total valuation is now the dominant predictor. Looking at the structure coefficients for the entire function, we see that pipelines valuation as percent (\%) of total valuation is positively related to market valuation.

Across both Functions, R\&D intensity-whether measured as absolute dollars or relative percent of valuation-is a significant determinant of financial performance. This finding supports our hypothesis $\mathrm{H}_{1}$ and $\mathrm{H}_{2}$. This is an encouraging finding because numerous large biopharmaceutical firms have invested heavily in developing R\&D activity and strengthen their competitive advantage. In terms of internal R\&D v. external R\&D, Fig. 1 shows us that on average, all of these companies used external partnering for $34 \%$ of their product pipelines (ranging from a low of $17 \%$ to a high of $57 \%$ ).

Without looking into dimensionality within and between variables set, Table 5 indicates that $\mathrm{R} \& \mathrm{D}$ intensity-in term of pipeline valuation as a percent (\%) of total valuation-has significant correlation $(p<0.01)$ with market value $(r=0.24)$ and price earning $(r=0.25)$. However, neither of the two significant correlations exceeded $r=0.7$, which is the level at which multicollinearity may become a problem.

Surprisingly, the result of the impact of pipeline valuation as a percent (\%) of total valuation on financial performance was inconsistent with our expectations $\left(\mathrm{H}_{3}\right)$. Further investigation using CCA, our full model across both function demonstrates that pipeline relative percent of valuation is the dominant predictor and positively related 
with market value and price earning but inversely related to the other performance variables, sales, and net income.

CCA indicates that our full model across all functions was statistically significant, $F(12,455.36)=69.36, p<0.001$. The effect size was 0.936 , which indicates that the full model explained a substantial portion of $93.6 \%$, of the variance shared between the variable sets. This result supports our hypothesis $\left(\mathrm{H}_{4}\right)$ that effectuation dimension has a high predictive power. Table 4 below summarizes our hypothesis testing results.

\section{Conclusions}

Given the rapid pace of change in biotechnology platforms, regulations, and payor environments, enhancing strategic decision-making for managing product pipeline productivity and risk is critical for analysts and investors and vital to firm and industry development. Biopharma firms must make resource allocation decisions on their relative levels of internal R\&D, strategic alliances, and/or mergers and acquisitions in furthering their pipelines and managing risk. Moreover, the predominant method of using DCF methodologies may lead to chronic underinvestment and performance.

We evaluated the integration of traditional DCF with an effectuation model of analysis. Unlike traditional financial models that begin with the end goal of assumed known cash flows and recursively solve for portfolio optimization, the effectuation model begins with resources that are readily available to the firm and then seeks to maintain strategic flexibility to take advantage of environmental contingencies as they arise. In that sense, it is more similar to a real options framework than to traditional discounted cash flow models.

Further, we juxtaposed the effectuation model against the more traditional model of discounting existing versus the dimensions of effectuation-means, affordable loss, partnerships, and expect the unexpected-in the context of the biopharma pipeline valuation. Using effectuation principles can provide insight into optimizing pipeline decisions by focusing on the logic of control rather than the logic of prediction. Effectuation principles suggest using the following dimensions may lead to addressing chronic underinvestment in the biopharma industry: (1) means to focus on what can be done with available resources rather than what ought to be done, (2) affordable loss rather than expected return, (3) partnerships rather than competitive analyses to create sources of operating and financial leverage, and (4) leverage contingencies rather than avoiding them (Sarasvathy, 2001, 2008).

Table 4 Hypothesis testing results

\begin{tabular}{|c|c|}
\hline Hypotheses & Results \\
\hline $\begin{array}{l}\mathrm{H}_{1} \text { : Biopharmaceutical companies with higher absolute } \mathrm{R} \& \mathrm{D} \text { expense will have higher } \\
\text { performance in terms of growth in revenues, net income, valuation, and Price-Earning (PE) } \\
\text { multiples relative to peer competitors. }\end{array}$ & Supported \\
\hline $\begin{array}{l}\mathrm{H}_{2:} \text { Biopharmaceutical companies with higher R\&D expense as percent (\%) of revenues will have } \\
\text { higher performance. }\end{array}$ & Supported \\
\hline $\begin{array}{l}\mathrm{H}_{3:} \text { Biopharmaceutical companies with higher pipeline valuation as a percent of overall valuation } \\
\text { will have higher performance. }\end{array}$ & Not supported \\
\hline $\begin{array}{l}\mathrm{H}_{4} \text { : Effectuation dimensions will have higher predictive power than the traditional discounted } \\
\text { value of present cash flow models. }\end{array}$ & Supported \\
\hline
\end{tabular}


We found that effectuation provides a useful strategic model that can be integrated into traditional DCF cash flow analyses to enhance decision-making. For example, instead of absolute focus on cash flows derived from a specific product or acquisition, considering the decision relative to existing capabilities and resources may lead to more investment which maximizes value (rather than disproportionately focused on avoiding risk of failure-see for example BMY String of Pearls strategy above). In this case, biopharmaceutical companies with higher absolute and relative R\&D expense levels were found to have higher performance in terms of growth in revenues, net income, valuation, and Price-Earning (PE) multiples relative to peer competitors.

Further, more aggressive investment into R\&D portfolios appears to reinforce competitive advantages. We found that biopharmaceutical companies with higher pipeline valuation as a percent of overall valuation also experienced higher performance over time, meaning that investors were able to discern and ascribe differential value between the pipeline values of different companies and those with larger overall market valuations had increased "means" to invest and further extend their dominant positions. Overall, these results suggest if conceived and operationalized in a way that fits the highly uncertain biopharma industry environment, applying elements of the effectuation model and mindset to biopharma pipeline valuation may provide a fruitful avenue for both practice and research. As such, it may be a useful framework for biotechnology industry managers, charged with accelerating technology platforms, building product pipelines, developing commercial products for addressing unmet medical needs, and managing significant binary risk.

In sum, we believe this study contributes to the research literature by expanding and extending the use of effectuation theory as an integrative framework with the predominant DCF NPV analysis for considering biopharmaceutical firm product pipeline development and risk management decision-making. Moreover, this is the first effectuation research to use empirical data versus prior effectuation analyses, which have relied on surveys of management perceptions. Further, our integration of effectuation and DCF provides a lens from which to explore emerging varieties of small and large company innovation in the biopharmaceutical industry.

\section{Endnotes}

${ }^{1}$ The US FDA Orphan Drug Designation program provides orphan status to drugs and biologics which are defined as those intended for the safe and effective treatment, diagnosis, or prevention of rare diseases/disorders that affect fewer than 200,000 people in the USA or that affect more than 200,000 persons but are not expected to recover the costs of developing and marketing a treatment drug.

${ }^{2}$ New biopharmaceutical products generally sequentially progress through the following steps: (1) conduct in vitro and in vivo preclinical testing to establish biological activity against the targeted disease and preliminary toxicology, (2) file an Investigational New Drug (IND) application to allow human clinical trials, (3) conduct Phase I, II, and III clinical trials to establish statistically significant safety and efficacy in humans, and (4) file a New Drug Application (NDA) for approval for a specific type and stage of disease (Wierenga and Eaton 2006). 


\section{Appendix 1}

Table 5 Descriptive statistics

\begin{tabular}{llrrrr}
\hline & Number & Minimum & Maximum & Mean & Std. deviation \\
\hline RnDExpense & 216 & 0.00 & 11.11 & 2.20 & 2.30 \\
RnDpercent & 216 & 0.00 & 12.50 & 0.28 & 0.89 \\
ValuePipeline & 179 & -0.23 & 1.00 & 0.72 & 0.28 \\
Sales & 216 & 0.00 & 67.22 & 14.99 & 16.21 \\
Income & 216 & -2.07 & 19.33 & 2.68 & 3.28 \\
MarketValue & 231 & 2.29 & 911.99 & 107.45 & 118.24 \\
PriceEarnings & 201 & -27.49 & 4185.76 & 104.63 & 338.94 \\
Valid N (listwise) & 179 & & & &
\end{tabular}

Table 6 Bivariate correlations

\begin{tabular}{|c|c|c|c|c|c|c|c|c|}
\hline & & RnDExpense & RnDpercent & $\begin{array}{l}\text { Value } \\
\text { Pipeline }\end{array}$ & Sales & Income & $\begin{array}{l}\text { Market } \\
\text { Value }\end{array}$ & $\begin{array}{l}\text { Price } \\
\text { Earnings }\end{array}$ \\
\hline \multirow[t]{2}{*}{ RnD expense } & Pearson correlation & 1 & -0.122 & $-0.641^{a}$ & $0.940^{\mathrm{a}}$ & $0.837^{a}$ & $0.165^{b}$ & $-0.163^{b}$ \\
\hline & Sig. (2-tailed) & & 0.074 & 0.000 & 0.000 & 0.000 & 0.015 & 0.026 \\
\hline \multirow[t]{2}{*}{ RnDpercent } & Pearson correlation & -0.122 & 1 & $0.174^{b}$ & $-0.135^{b}$ & -0.119 & -0.068 & $0.144^{b}$ \\
\hline & Sig. (2-tailed) & 0.074 & & 0.020 & 0.047 & 0.080 & 0.316 & 0.049 \\
\hline \multirow[t]{2}{*}{ ValuePipeline } & Pearson correlation & $-0.641^{a}$ & $0.174^{b}$ & 1 & $-0.619^{a}$ & $-0.674^{\mathrm{a}}$ & $0.239^{a}$ & $0.245^{\mathrm{a}}$ \\
\hline & Sig. (2-tailed) & 0.000 & 0.020 & & 0.000 & 0.000 & 0.001 & 0.001 \\
\hline \multirow[t]{2}{*}{ Sales } & Pearson correlation & $0.940^{\mathrm{a}}$ & $-0.135^{b}$ & $-0.619^{a}$ & 1 & $0.888^{a}$ & $0.203^{a}$ & $-0.171^{b}$ \\
\hline & Sig. (2-tailed) & 0.000 & 0.047 & 0.000 & & 0.000 & 0.003 & 0.020 \\
\hline \multirow[t]{2}{*}{ Income } & Pearson correlation & $0.837^{\mathrm{a}}$ & -0.119 & $-0.674^{a}$ & $0.888^{\mathrm{a}}$ & 1 & $0.200^{a}$ & $-0.184^{b}$ \\
\hline & Sig. (2-tailed) & 0.000 & 0.080 & 0.000 & 0.000 & & 0.003 & 0.012 \\
\hline \multirow[t]{2}{*}{ MarketValue } & Pearson correlation & $0.165^{b}$ & -0.068 & $0.239^{a}$ & $0.203^{a}$ & $0.200^{a}$ & 1 & 0.108 \\
\hline & Sig. (2-tailed) & 0.015 & 0.316 & 0.001 & 0.003 & 0.003 & & 0.128 \\
\hline \multirow[t]{2}{*}{ PriceEarnings } & Pearson correlation & $-0.163^{b}$ & $0.144^{b}$ & $0.245^{\mathrm{a}}$ & $-0.171^{b}$ & $-0.184^{b}$ & 0.108 & 1 \\
\hline & Sig. (2-tailed) & 0.026 & 0.049 & 0.001 & 0.020 & 0.012 & 0.128 & \\
\hline
\end{tabular}

${ }^{\text {a }}$ Correlation is significant at the 0.01 level (2-tailed)

${ }^{\mathrm{b}}$ Correlation is significant at the 0.05 level (2-tailed)

Table 7 Eigenvalues and canonical correlations

\begin{tabular}{lccccc}
\hline Function no. & Eigenvalue & Pct. & Cum. pct. & Canon cor. & Sq. cor \\
\hline 1 & 9.253 & 94.725 & 94.725 & 0.950 & 0.902 \\
2 & 0.494 & 5.053 & 99.778 & 0.575 & 0.330 \\
3 & 0.022 & 0.222 & 100.000 & 0.146 & 0.021 \\
\hline
\end{tabular}

Table 8 Multivariate tests of significance

\begin{tabular}{llcccc}
\hline Test name & Value & Exact F & Hypoth. DF & Error DF & Sig. of F \\
\hline Pillais & 1.25416 & 31.24925 & 12.00 & 522.00 & 0.000 \\
Hotellings & 9.76808 & 138.92375 & 12.00 & 512.00 & 0.000 \\
Wilks & 0.06392 & 69.3565 & 12.00 & 455.36 & 0.000 \\
Roys & 0.90247 & & & \\
\hline
\end{tabular}


Table 9 Dimension reduction analysis

\begin{tabular}{llllll}
\hline Function & Wilks L. & F & Hypoth. DF & Error DF & Sig. of F \\
\hline 1 TO 3 & 0.064 & 69.357 & 12.000 & 455.360 & 0.000 \\
2 TO 3 & 0.655 & 13.570 & 6.000 & 346.000 & 0.000 \\
3 TO 3 & 0.979 & 1.885 & 2.000 & 174.000 & 0.155 \\
\hline
\end{tabular}

Table 10 Standardized canonical coefficients for dependent variables

\begin{tabular}{llll}
\hline & Function no. & \\
\hline Variable & 1 & 2 & 3 \\
Sales & 1.032 & 1.326 & -0.261 \\
Income & -0.037 & -1.541 & 0.552 \\
MarketVa & -0.030 & 0.746 & -0.180 \\
PriceEar & -0.027 & 0.140 & 1.015 \\
\hline
\end{tabular}

Table 11 Correlations between dependent and canonical variables

\begin{tabular}{llll}
\hline & Function no. & \\
\hline Variable & 1 & 2 & 3 \\
Sales & 0.999 & 0.019 & 0.026 \\
Income & 0.897 & -0.256 & 0.088 \\
MarketVa & 0.117 & 0.725 & -0.043 \\
PriceEar & -0.210 & 0.273 & 0.937 \\
\hline
\end{tabular}

Table 12 Standardized canonical coefficients for independent variables

\begin{tabular}{llll}
\hline & Canonical variable & \\
\hline Variable & 1 & 2 & 3 \\
RnDExpen & 0.943 & 0.846 & 0.316 \\
RnDperce & -0.155 & -0.094 & 1.002 \\
ValuePip & -0.030 & 1.308 & -0.004 \\
\hline
\end{tabular}

Table 13 Correlations between independent and canonical variables

\begin{tabular}{llll}
\hline \multicolumn{4}{c}{ Canonical variable } \\
\hline Variable & 1 & 2 & 3 \\
RnDExpen & 0.988 & 0.023 & 0.155 \\
RnDperce & -0.314 & -0.004 & 0.949 \\
ValuePip & -0.661 & 0.749 & -0.032 \\
\hline
\end{tabular}

Competing interests

The authors declare that they have no competing interests.

Authors' contributions

All authors contributed to this project equally from the inception to the end.

\section{Author details}

${ }^{1}$ Portland State University, Portland, USA. ${ }^{2}$ Creighton University, Omaha, USA. ${ }^{3}$ Willamette University, Salem, USA.

Received: 1 October 2015 Accepted: 17 November 2015

Published online: 03 December 2015

References

Afifi, A. A. A., \& Clark, V. A. (2004). Computer-aided multivariate analysis (Vol. 62). CRC Press: Boca Raton. 
Ahn, M. J., \& Meeks, M. (2008). Building a conducive environment for life science-based entrepreneurship and industry clusters. Journal of Commercial Biotechnology, 14(1), 20-30.

Ahn, M. J., Meeks, M., Davenport, S., \& Bednarek, R. (2010). Exploring technology agglomeration patterns for multinational pharmaceutical and biotechnology firms. Journal of Commercial Biotechnology, 16(1), 17-32.

Ahn, M. J., Wu, W., \& Rahman, Q. (2010). Medarex: realizing its potential? In M. J. Ahn, M. A. Alvarez, A. D. Meyers, \& A. S. York (Eds.), Building the case for biotechnology. Logos Press: Washington, DC.

Augier, M., \& Sarasvathy, S. D. (2004). Integrating evolution, cognition and design: extending Simonian perspectives to strategic organization. Strategic Organization, 2(2), 169-204.

Barney, J. (1991). Firm resources and sustained competitive advantage. Journal of Management, 17(1), 99-120.

Beach, R. (2011). Microcap pharmaceutical firms: linking drug pipelines to market value. Journal of Health Care Finance, 39(2), 82-92.

Brettel, M., Mauer, R., Engelen, A., \& Küpper, D. (2012). Corporate effectuation: entrepreneurial action and its impact on R\&D project performance. Journal of Business Venturing, 27(2), 167-184.

Brink, J., \& Holmén, M. (2009). Capabilities and radical changes of the business models of new bioscience firms. Creativity and Innovation Management, 18(2), 109-120.

Darlington, R. B., Weinberg, S. L., \& Walberg, H. J. (1973). Canonical variate analysis and related techniques. Review of Educational Research, 43(4), 433-454.

Dew, N., Sarasvathy, S. D., \& Venkataraman, S. (2004). The economic implications of exaptation. Journal of Evolutionan Economics, 14(1), 69-84.

DiMasi, J. A. (2013). Clinical success rates for new cancer drugs doubled from the mid-1990s to early-2000s. Retrieved August 10, 2013, from http://csdd.tufts.edu.

Fan, X. (1997). Canonical correlation analysis and structural equation modeling: what do they have in common? Structural Equation Modeling: A Multidisciplinary Journal, 4(1), 65-79.

Fernandez, S., \& Arabi, A. (2013). Azn/lower EPS reflects higher spend; pipeline visibility a key focus/market perform. Retrieved August 16, 2013, from http://portal.leerink.com/.

Ford, C. M., Sharfman, M. P., \& Dean, J. W. (2008). Factors associated with creative strategic decisions. Creativity and Innovation Management, 17(3), 171-185.

Gulati, R., \& Higgins, M. C. (2003). Which ties matter when? The contingent effects of interorganizational partnerships on IPO success. Strategic Management Journal, 24(2), 127-144.

Hair, J. F., Jr., Anderson, R. E., \& Tatham, R. L. (1986). Multivariate data analysis with readings. Macmillan Publishing Co., Inc: New York.

Harrison, M., \& Lerer, L. (2002). Real options for biotechnology valuation. Nature Biotechnology, 20(3), 223-223.

Hartmann, M., \& Hassan, A. (2006). Application of real options analysis for pharmaceutical R\&D project valuation-empirical results from a survey. Research Policy, 35(3), 343-354.

Hemlin, S. (2009). Creative knowledge environments: an interview study with group members and group leaders of university and industry R\&D groups in biotechnology. Creativity and Innovation Management, 18(4), 278-285.

Hemphälä, J., \& Magnusson, M. (2012). Networks for innovation—but what networks and what innovation? Creativity and Innovation Management, 21(1), 3-16.

Hitt, M. A., \& Duane, R. (2002). The essence of strategic leadership: managing human and social capital. Journal of Leadership \& Organizational Studies, 9(1), 3-14.

Iskin, I., Daim, T. U., \& Cutar, A. (2011). Do investments in research and development translate to sales? International Journal of Business Innovation and Research, 5(5), 510-525.

Kirchhoff, M., \& Schiereck, D. (2011). Determinants of M\&A success in the pharmaceutical and biotechnological industry. IUP Journal of Business Strategy, 8(1).

Kola, I., \& Landis, J. (2004). Can the pharmaceutical industry reduce attrition rates? Nature Reviews Drug discovery, $3(8), 711-716$.

Kumaraswamy, A. (1998). An organizational real-options perspective of firms' R\&D: Empirical evidence. Chicago: Paper presented at the 2nd Annual Conference on Real Options: theory meets practice.

Levine, M.S. (1977). Canonical analysis and factor comparison (Vol. 6). Sage

Lindgren, M., \& Packendorff, J. (2011). Issues, responsibilities and identities: a distributed leadership perspective on biotechnology R\&D management. Creativity and Innovation Management, 20(3), 157-170.

Löfqvist, M. (2009). On the valuation of "big pharma's" research pipelines.

Makadok, R. (2001). Toward a synthesis of the resource-based and dynamic-capability views of rent creation. Strategic Management Journal, 22(5), 387-401.

Newton, D. P., Paxson, D. A., \& Widdicks, M. (2004). Real R\&D options. International Journal of Management Reviews, 5(2), 113-130.

Nicholson, S., Danzon, P. M., \& McCullough, J. S. (2002). Biotech-pharmaceutical alliances as a signal of asset and firm quality: National Bureau of Economic Research.

Nickisch, K., \& Bode-Greuel, K. M. (2013). NPV modelling for the selection of value-creating biosimilar development candidates. Journal of Commercial Biotechnology, 19(1).

Pammolli, F., Magazzini, L., \& Riccaboni, M. (2011). The productivity crisis in pharmaceutical R\&D. Nature Reviews Drug Discovery, 10(6), 428-438.

Pavlou, A. K., \& Belsey, M. J. (2005). Biopharma licensing and M\&A trends. Nature Reviews Drug Discovery, 4(4), 273-274.

Pedhazur, E. J. (1997). Multiple regression in behavioral research: explanation and prediction.

Piccart-Gebhart, M. J. (2014). The 41st David A. Karnofsky memorial award lecture: academic research worldwide—quo vadis? Journal of Clinical Oncology, 32(4), 347-354.

President's Council of Advisors on Science and Technology. (2012). President's council of advisors on science and technology: propelling innovation in drug discovery, development, and evaluation - policy and medicine. Retrieved August 6, 2013, from http://www.policymed.com/

Read, S., Dew, N., Sarasvathy, S. D., Song, M., \& Wiltbank, R. (2009). Marketing under uncertainty: the logic of an effectual approach. Journal of Marketing, 73(3), 1-18. 
Roy, A. (2012). Stifling new cures: the true cost of lengthy clinical drug trials. Project FDA report. New york: Manhattan Institute for Policy Research, 5.

Sarasvathy, S. D. (2001). Causation and effectuation: toward a theoretical shift from economic inevitability to entrepreneurial contingency. Academy of Management Review, 26(2), 243-263.

Sarasvathy, S. D. (2008). Effectuation: elements of entrepreneurial expertise. Edward Elgar Publishing: United Kingdom.

Sherry, A., \& Henson, R. K. (2005). Conducting and interpreting canonical correlation analysis in personality research: a user-friendly primer. Journal of Personality Assessment, 84(1), 37-48.

Stewart, J. J., Allison, P. N., \& Johnson, R. S. (2001). Putting a price on biotechnology. Nature Biotechnology, 19(9), 813-818.

Su, Y.-S., Tsang, E. W., \& Peng, M. W. (2009). How do internal capabilities and external partnerships affect innovativeness? Asia Pacific Journal of Management, 26(2), 309-331.

Thompson, B. (1985). Heuristics for teaching multivariate general linear model techniques (Annual meeting of the American Educational Research Journal, Chicago, IL.(ERIC Document Reproduction Service No. ED 262 073)).

Thompson, B. (1991). A primer on the logic and use of canonical correlation analysis. Measurement and Evaluation in Counseling and Development, 24(2), 80-95.

Tucker, R., Chase, L., Monge, P., \& Cappella, J. (1980). Canonical correlation (Multivariate techniques in human communication research, 205-228).

Wierenga, D. E., \& Eaton, C. R. (2006). Drug development and approval process (USA). Retrieved Dec 17, 2009, from http:// www.mr-tip.com/

Wiltbank, R., Read, S., Dew, N., \& Sarasvathy, S. D. (2009). Prediction and control under uncertainty: outcomes in angel investing. Journal of Business Venturing, 24(2), 116-133.

York, A. S., Dunham, L. M., \& Ahn, M. (2011). Vertical versus horizontal integration in the biopharma industry: the link between acquisition announcements and stock market performance. Advances in Mergers \& Acquisitions, 10, 121-143.

Submit your manuscript to a SpringerOpen ${ }^{\circ}$ journal and benefit from:

- Convenient online submission

Rigorous peer review

- Immediate publication on acceptance

- Open access: articles freely available online

- High visibility within the field

Retaining the copyright to your article

Submit your next manuscript at $\gg$ springeropen.com 